\title{
Clinical Reasoning: A 56-year-old woman with acute vertigo and diplopia
}

Rishi Sharma, Tia Chakraborty, MD, Francis K. Buadi, MD, Elena Beam, MD, Vincent S. Pureza, MD, Gabriel L. Pagani-Estevez, MD, and Eoin P. Flanagan, MBBCh

Neurology ${ }^{\circledR}$ 2018;90:748-752. doi:10.1212/WNL.0000000000005337
Correspondence

Dr. Flanagan

flanagan.eoin@mayo.edu

\section{Section 1}

A 56-year-old woman with a recent diagnosis of primary light-chain (AL) (lambda type) amyloidosis complicated by mild infiltrative cardiomyopathy and autonomic neuropathy had sudden onset vertigo and diplopia. She also had a history of hyperlipidemia and hypothyroidism. The diplopia was binocular and worsened on rightward gaze. The patient denied headache, fever, neck stiffness, photophobia, confusion, tinnitus, or impaired hearing. Prior to presentation, she had completed her third cycle of chemotherapy at an outside facility for AL amyloidosis with bortezomib, lenalidomide, and dexamethasone and had come to our facility for a second opinion regarding her amyloidosis when this event happened. Her other medications included aspirin, atorvastatin, levothyroxine, spironolactone, torasemide, midodrine, calcium, and vitamin D. She did not smoke or use alcohol. Her vital signs included a temperature of $36.4^{\circ} \mathrm{C}$, blood pressure $109 / 82 \mathrm{~mm} \mathrm{Hg}$, and heart rate 80 . Her general examination revealed cachexia and bilateral pitting edema. Her neurologic examination revealed a right sixth cranial nerve palsy, direction-changing nystagmus, mild right-sided dysdiadochokinesis, and mild weakness (Medical Research Council grade 4 of 5) of the deltoids and iliopsoas bilaterally; head impulse test was negative and there was no skew deviation. Her mental status, gait, reflexes, and sensory examination were within normal limits. A skin examination revealed a scattered pustular right-sided rash in the peri-auricular region, neck, chest, and thigh, which the patient mentioned was of new onset. There was no periorbital purpura or macroglossia.

\section{Questions for consideration:}

1. What is the localization?

2. What is the differential diagnosis?

\section{GO TO SECTION 2}

From the Department of Neurology (R.S., T.C., G.L.P.-E., E.P.F.) and Divisions of Hematology (F.K.B.), Infectious Disease (E.B.), and Hospital Internal Medicine, Department of Medicine (V.S.P.), Mayo Clinic, Rochester, MN; and College of Biological Sciences (R.S.), University of Minnesota, Minneapolis.

Go to Neurology.org/N for full disclosures. Funding information and disclosures deemed relevant by the authors, if any, are provided at the end of the article. 


\section{Section 2}

The constellation of diplopia, sixth nerve palsy, directionchanging nystagmus, and negative head impulse test clinically suggested a central rather than peripheral etiology for vertigo. The most likely single localization was the pons. The absence of a horizontal gaze palsy favored a fascicular rather than nuclear sixth nerve palsy. The differential diagnosis included the following:

1. Ischemic stroke (e.g., basilar thrombosis, lacunar, cardioembolic [given cardiomyopathy])

2. Posterior fossa hemorrhage (in setting of thrombocytopenia)

3. Infectious rhomboencephalitis (e.g., listeria, other etiologies [viral, fungal])

4. Paraneoplastic/autoimmune rhomboencephalitis

5. Toxic/metabolic encephalopathy (e.g., medicationinduced, osmotic demyelination)

6. Demyelination (e.g., multiple sclerosis)

The differential diagnosis of an acute neurologic episode in a patient undergoing chemotherapy for malignancy should include a direct toxic effect of the chemotherapy, an indirect consequence of the treatment (e.g., infection from the associated immunosuppression), direct neurologic involvement of the neoplasm, an indirect consequence of the neoplasm, or a paraneoplastic phenomenon. The acuity suggested a vascular etiology, and initial imaging with CT head was normal excluding a posterior fossa hemorrhage, which the patient was at risk for given that initial blood tests revealed a thrombocytopenia (platelets $114,000 / \mathrm{mm}^{3}$; normal, $150-450$ ). An EKG revealed normal sinus rhythm and a cardiac MRI 3 months prior revealed a preserved ejection fraction of 59\%; $\mathrm{AL}$ amyloidosis increases the risk of ischemic stroke, often from a cardioembolic source. ${ }^{1}$ CT angiogram was normal excluding a large vessel occlusion (e.g., basilar thrombosis), a neurologic emergency important to exclude in the setting of an acute brainstem syndrome. An MRI head without contrast was undertaken 18 hours after onset to assess for a small infarct in the brainstem, but was without definitive abnormality and excluded other inflammatory disorders (e.g., multiple sclerosis). Paraneoplastic syndromes are not typically encountered with AL amyloidosis and were believed to be unlikely. Quadriparesis and brainstem findings could suggest osmotic demyelination but a recent serum sodium had been normal, and the weakness was proximal, suggesting myopathy from recent steroid use as a more likely cause. Thiamine deficiency is another possibility in a cachectic patient with diplopia, but the ataxia was mild and appendicular (rather than truncal). The presence of a rash and vertigo led to investigations for alternative etiologies, although testing serum thiamine level and empiric administration of thiamine may have been reasonable while investigations were ongoing.

\section{Question for consideration:}

1. Does a negative MRI with diffusion-weighted imaging exclude a small brainstem stroke?

\section{GO TO SECTION 3}




\section{Section 3}

Diffusion-weighted imaging (DWI) with MRI has limited sensitivity for small brainstem strokes particularly within the first 48 hours after onset. ${ }^{2}$ This may be due to insufficient signal to noise ratio, poor spatial resolution, magnetic susceptibility artifacts in the brainstem, or location of the imaging slice. In our patient, the first MRI with DWI and apparent diffusion coefficient sequences was performed less than 24 hours after symptom onset and reported to be without definitive abnormality. Repeat MRI with gadolinium performed at 72 hours after onset showed a small area of restricted diffusion in the dorsal pons adjacent to the fourth ventricle without gadolinium enhancement (figure); in retrospect, subtle restricted diffusion may have been present on the initial MRI (A1 and A2, arrows). The infarct was in the region of the right sixth cranial nerve nucleus and its pathway within the dorsal pons.

\section{Questions for consideration:}

1. What is the diagnosis and how was it confirmed?

2. How could this have been prevented?
Figure MRI head

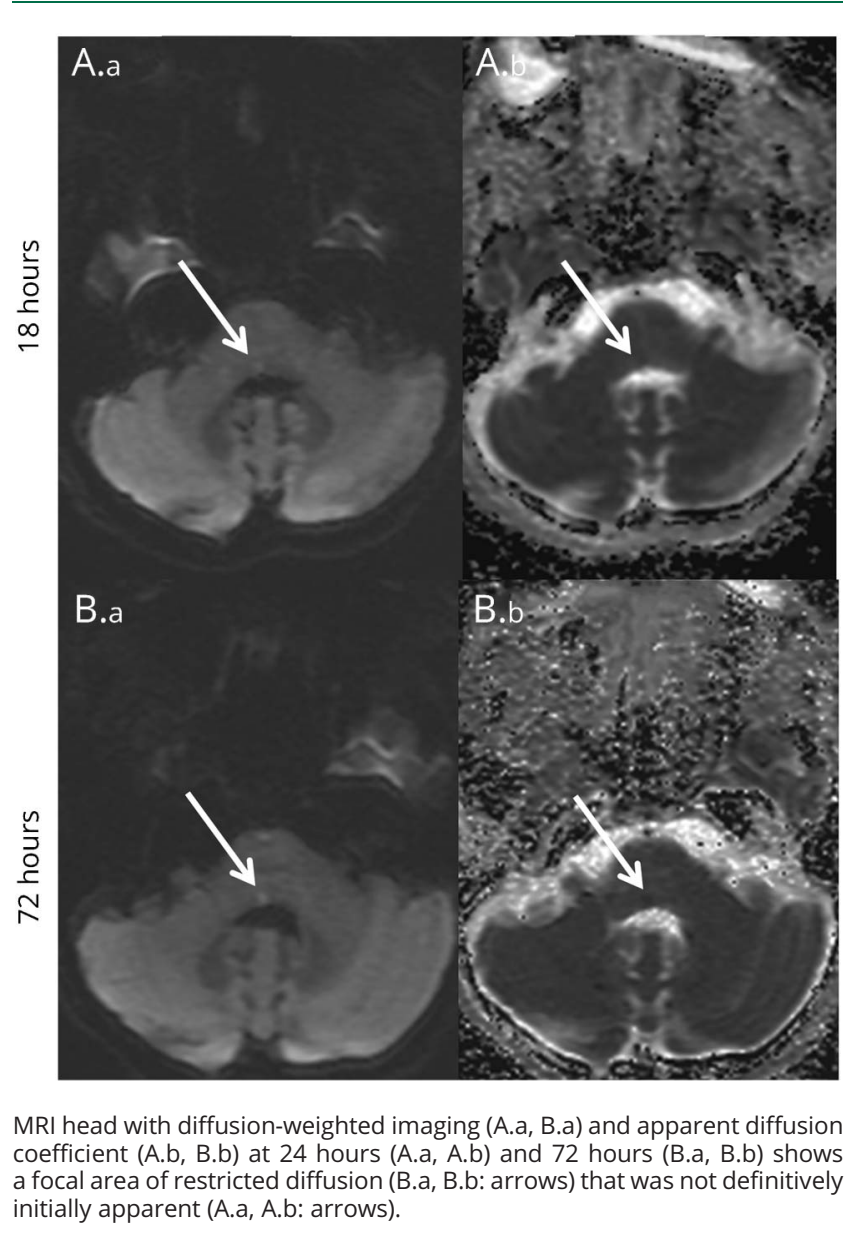




\section{Section 4}

On initial presentation, a scattered pustular rash was noted on the right side. A swab from a right neck lesion had a positive varicella-zoster virus (VZV) PCR. The presence of disseminated VZV in an immunocompromised host concomitant to the neurologic onset, the known association of VZV with vasculopathy, the MRI appearance favoring small vessel disease rather than embolism (single small infarct in a deep location without other infarcts), and the preserved ejection fraction led us to undertake a lumbar puncture as the next diagnostic step; however, obtaining a transesophageal or transthoracic echocardiogram would have been a reasonable alternative to assess for a cardioembolic source. CSF analysis revealed 350 white blood cells $/ \mathrm{mm}^{3}$ (normal, 0-5) with a lymphocytic predominance (86\%), 127 red blood cells $/ \mathrm{mm}^{3}$, a protein of $186 \mathrm{mg} / \mathrm{dL}$ (normal $0-35$ ), and glucose of $34 \mathrm{mg} / \mathrm{dL}$. VZV PCR was positive in CSF. The final diagnosis was disseminated VZV (based on skin involvement of multiple dermatomes) complicated by nervous system involvement with VZV vasculopathy the presumed mechanism of the pontine infarct. The patient was placed on IV acyclovir $10 \mathrm{mg} / \mathrm{kg}$ every 8 hours for 21 days. Four days later, she developed a right peripheral facial nerve palsy and prednisone $60 \mathrm{mg} / \mathrm{d}$ for 7 days was recommended after multidisciplinary discussion between infectious disease and neurology teams. The ipsilateral right facial nerve palsy may have been from extension of the pontine infarct as the facial nerve in its initial course wraps around the sixth nerve nucleus and closely approximates the sixth cranial nerve before continuing ventrolaterally to emerge from the lateral pons. Alternative explanations included the accompanying brainstem encephalitis or an extrapontine facial nerve mononeuropathy.

Many studies have shown a significant increase in VZV reactivation in bortezomib-treated patients with rates of up to $40 \%$ reported. ${ }^{3}$ Therefore, antiviral prophylaxis with valacyclovir or acyclovir is generally recommended in those receiving bortezomib. One study compared acyclovir $400 \mathrm{mg}$ once daily to 3 times daily dosing and both regimens were shown to protect from the risk of VZV reactivation. ${ }^{4}$ Our patient did not receive VZV prophylaxis during her bortezomib use at the outside facility; if utilized, it may have prevented the development of disseminated VZV.

\section{Discussion}

With increasing use of novel chemotherapeutics for hematologic and other malignancies, it is important for neurologists to be aware of the potential for direct and indirect neurologic toxicity and understand how to prevent such complications. This case serves as a reminder of the potential for VZV to cause vasculopathy and illustrates an indirect neurologic complication of bortezomib.
Bortezomib is a selective and reversible proteasome inhibitor that prevents degradation of ubiquinated proteins. This mechanism of action promotes apoptosis and thus it has shown benefit in a variety of hematologic malignancies. Bortezomib causes indirect inhibition of nuclear factor-KB (NF-KB), which controls DNA transcription, cytokine production, and cell survival. Activation of the NF-KB pathway causes a cellular antiviral response, including production of $\alpha / \beta$-interferon, cytokines, and other proteins that restrict viral infection; this pathway's inhibition may explain the risk of VZV reactivation with bortezomib. ${ }^{5}$

Following primary VZV infection, the virus becomes dormant in ganglionic neurons. It reactivates later due to decreased VZV-specific cell-mediated immunity that occurs with aging or, as in this case, in the setting of immunosuppression. VZV reactivation can have many neurologic manifestations including zoster (shingles), herpes zoster ophthalmicus, meningitis, encephalitis, ventriculitis, myelopathy, cerebellitis, retinal necrosis, or limb paresis. ${ }^{6,7}$ VZV vasculopathy is thought to arise from direct infection of the large or small cerebral blood vessels resulting in thrombosis, necrosis, dissection, or aneurysms. ${ }^{7}$ VZV vasculopathy can occur at any age and its frequency may be on the increase with the availability of novel therapeutics that particularly predispose to VZV reactivation. Diagnosis of VZV vasculopathy can be difficult as magnetic resonance angiography, CT angiography, or conventional angiogram are negative in up to $30 \%$, possibly due to the isolated small vessel vasculitis that occurs in over a third of cases. ${ }^{8}$ Detection of VZV DNA in CSF by PCR helps confirm the diagnosis but CSF VZV serology (immunoglobulin $\mathrm{G}$ and $\mathrm{M}$ ) is more sensitive particularly in those without immunosuppression or a delayed presentation. Acyclovir is the treatment of choice $(10 \mathrm{mg} / \mathrm{kg})$ each 8 hours $\times 14-21$ days and some advocate using concomitant oral steroids, as we did.

\section{Author contributions}

R. Sharma: drafting manuscript, acquisition of data, analysis and interpretation. Dr. Chakraborty: analysis and interpretation, critical revision for important intellectual content. Dr. Buadi: analysis and interpretation, critical revision for important intellectual content. Dr. Beam: analysis and interpretation, critical revision for important intellectual content. Dr. Pureza: analysis and interpretation, critical revision for important intellectual content. Dr. Pagani-Estevez: analysis and interpretation, critical revision for important intellectual content. Dr. Flanagan: acquisition of data, analysis and interpretation, critical revision for important intellectual content, study supervision.

\section{Study funding}

No targeted funding reported.

\section{Disclosure}

The authors report no disclosures relevant to the manuscript. Go to Neurology.org/N for full disclosures. 


\section{References}

1. Zubkov AY, Rabinstein AA, Dispenzieri A, Wijdicks EF. Primary systemic amyloidosis with ischemic stroke as a presenting complication. Neurology 2007;69:1136-1141.

2. Edlow BL, Hurwitz S, Edlow JA. Diagnosis of DWI-negative acute ischemic stroke: a meta-analysis. Neurology 2017;89:256-262.

3. Chanan-Khan A, Sonneveld P, Schuster MW, et al. Analysis of herpes zoster events among bortezomib-treated patients in the phase III APEX study. J Clin Oncol 2008; 26:4784-4790.

4. Pour L, Adam Z, Buresova L, et al. Varicella-zoster virus prophylaxis with low-dose acyclovir in patients with multiple myeloma treated with bortezomib. Clin Lymphoma Myeloma 2009;9:151-153.
5. Jones JO, Arvin AM. Inhibition of the NF-kappaB pathway by varicellazoster virus in vitro and in human epidermal cells in vivo. J Virol 2006;80: 5113-5124.

6. Gilden DH, Kleinschmidt-DeMasters BK, LaGuardia JJ, Mahalingam R, Cohrs RJ Neurologic complications of the reactivation of varicella-zoster virus. N Engl J Med 2000;342:635-645.

7. Gilden D, Cohrs RJ, Mahalingam R, Nagel MA. Varicella zoster virus vasculopathies: diverse clinical manifestations, laboratory features, pathogenesis, and treatment. Lancet Neurol 2009;8:731-740.

8. Nagel MA, Cohrs RJ, Mahalingam R, et al. The varicella zoster virus vasculopathies: clinical, CSF, imaging, and virologic features. Neurology 2008;70:853-860.

\section{Subspecialty Alerts by E-mail!}

Customize your online journal experience by signing up for e-mail alerts related to your subspecialty or area of interest. Access this free service by clicking on the "My Alerts" link on the home page. An extensive list of subspecialties, methods, and study design choices will be available for you to choose from-allowing you priority alerts to cutting-edge research in your field!

\section{The AAN Has Your Back!}

Every day, the AAN is fighting for you. From actively lobbying members of Congress for common sense legislation, to meeting with regulators to demonstrate the value of neurology and reduce regulatory hassles, the Academy is forcefully countering any threats to your profession and patient access to care. Learn more at AAN.com/policy-and-guidelines/advocacy, read the bimonthly Capitol Hill Report and monthly $A A N n e w s{ }^{\circledR}$ member magazine, and respond to Advocacy Action Alert emails when we invite you to share your voice with Congress.

Get into the conversation at \#AANAdvocacy.

\section{Disputes \& Debates: Rapid online correspondence}

The editors encourage comments on recent articles through Disputes \& Debates:

Access an article at Neurology.org/ $N$ and click on "COMMENT" beneath the article header. Responses will be posted within 3 business days.

Before submitting a comment to Disputes \& Debates, remember the following:

- Disputes \& Debates is restricted to comments about studies published in Neurology within the last eight weeks

- Read previously posted comments; redundant comments will not be posted

- Your submission must be 200 words or less and have a maximum of five references; reference one must be the article on which you are commenting

- You can include a maximum of five authors (including yourself) 


\section{Neurology}

\section{Clinical Reasoning: A 56-year-old woman with acute vertigo and diplopia}

Rishi Sharma, Tia Chakraborty, Francis K. Buadi, et al.

Neurology 2018;90;748-752

DOI 10.1212/WNL.0000000000005337

\section{This information is current as of April 16, 2018}

\section{Updated Information \& Services}

Supplementary Material

\section{References}

\section{Citations}

Subspecialty Collections

\section{Permissions \& Licensing}

Reprints including high resolution figures, can be found at: http://n.neurology.org/content/90/16/748.full

Supplementary material can be found at: http://n.neurology.org/content/suppl/2018/04/16/WNL.0000000000005 337.DC1

This article cites 8 articles, 5 of which you can access for free at: http://n.neurology.org/content/90/16/748.full\#ref-list-1

This article has been cited by 2 HighWire-hosted articles: http://n.neurology.org/content/90/16/748.full\#\#otherarticles

This article, along with others on similar topics, appears in the following collection(s):

Other toxicology

http://n.neurology.org/cgi/collection/other_toxicology

Viral infections

http://n.neurology.org/cgi/collection/viral_infections

Information about reproducing this article in parts (figures,tables) or in its entirety can be found online at:

http://www.neurology.org/about/about_the_journal\#permissions

Information about ordering reprints can be found online: http://n.neurology.org/subscribers/advertise

Neurology ${ }^{\circledR}$ is the official journal of the American Academy of Neurology. Published continuously since 1951, it is now a weekly with 48 issues per year. Copyright @ 2018 American Academy of Neurology. All rights reserved. Print ISSN: 0028-3878. Online ISSN: 1526-632X.

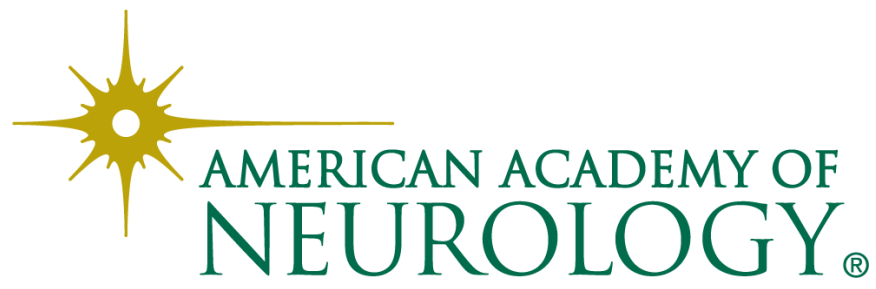

